\title{
Acute promyelocytic leukemia successfully treated also in elderly patients with significant comorbidities: a 20-year single-center experience
}

\author{
T. SZOTKOWSKI ${ }^{1, *}$, E. FABER ${ }^{1}$, J. HUBACEK ${ }^{1}$, L. RAIDA ${ }^{1}$, P. ROHON ${ }^{1}$, A. KUBA ${ }^{1}$, Z. PIKALOVA ${ }^{1}$, M. HOLZEROVA ${ }^{1}$, M. DIVOKA ${ }^{1}$, M. JAROSOVA ${ }^{1}$, \\ J. VRBKOVA ${ }^{2}$, T. PAPAJIK ${ }^{1}$, K. INDRAK ${ }^{1}$ \\ ${ }^{1}$ Department of Haemato-oncology, Faculty of Medicine and Dentistry, Palacky University Olomouc; ${ }^{2}$ Institute of Molecular and Translational \\ Medicine, Faculty of Medicine and Dentistry, Palacky University Olomouc \\ *Correspondence: tszotkowski@seznam.cz
}

Received April 7, 2014 / Accepted May 22, 2014

\begin{abstract}
Acute promyelocytic leukemia is a unique entity among acute leukemias. Introduction of all-trans retinoic acid and, subsequently, arsenic trioxide in its treatment has markedly improved treatment outcomes for this once frequently fatal disease. Improved outcomes have also been observed in elderly patients, including those in whom standard intensive therapy is contraindicated because of comorbidities.

In our center, a total of 60 APL patients were treated in 1993-2013, of whom 9 were aged 60 or more years. Although most of them had significant comorbidities at the time of diagnosis, eight achieved complete remission. At the time of the analysis, six patients were alive and in long-term remission; two patients died of causes other than APL. The median followup was 59 months.

Included is case report of a patient with a high comorbidity score whose treatment was markedly reduced and individualized.

Our experience shows that, in APL patients a curative approach is generally tolerated and should always be attempted regardless of age and comorbidities.
\end{abstract}

Key words: APL - elderly patients - comorbidity

Acute promyelocytic leukemia (APL) is a unique entity among acute myeloid leukemias (AML). It is characterized by specific genetic ( $\mathrm{t}(15 ; 17)(\mathrm{q} 22 ; \mathrm{q} 21)$ and the PML/RAR $\alpha$ fusion gene in $99 \%$ of cases), morphological (M3/M3v) and clinical (coagulation abnormalities with a high risk of fatal bleeding) aspects requiring specific treatment approaches [1-4]. APL accounts for 5-15\% of AML cases [5,6]. Addition of all-trans retinoic acid (ATRA) to anthracycline-based chemotherapy more than doubled the rates of complete remission (CR), significantly improved overall survival and disease-free survival in APL patients; today, approximately $70-80 \%$ of patients may be cured $[7,8]$. Introduction of arsenic trioxide (ATO)(2007), a drug even more effective than ATRA, has continued to improve the potential of current therapy of the condition [9].

Given the highly effective current therapy and the fatal course of the disease within a short period of time if it is not initiated, ATRA is immediately administered to all patients irrespective of their age. Further therapy is either based on standard protocols or, in case of a severe previous comorbidity, reduced adequately and tailored to a particular patient.

\section{Patients and methods}

In our center, ATRA has been available for treating APL for over 20 years. Between February 1993 and the end of 2013, a total of 60 patients were treated, of whom 9 were aged 60 or more years on treatment initiation. The objective of the study was to retrospectively assess the treatment success rate and experience with treatment individualization in this subgroup of patients.

The entire group comprised 60 patients (34 males and 26 females), with ages ranging from 19 to 73 years (median, 43.5 years; mean 45.2 years). In all patients' leukemic promyelocytes, the $\mathrm{t}(15 ; 17)(\mathrm{q} 22 ; \mathrm{q} 21)$ translocation and the PML/RAR fusion gene were confirmed. Hypergranular morphology of the tumor cells was noted in 57 patients; three patients had 
the microgranular variant $(\mathrm{M} 3 \mathrm{v})$ of the disease. According to a predictive model by Sanz et al. [10], 17 patients (28.3\%) were in a low-risk group, 33 (55\%) were in an intermediaterisk group and 10 (16.7\%) were in a high-risk group. Fifty-six patients had no previous cytotoxic therapy in their history; four patients were diagnosed as having leukemia secondary to earlier chemotherapy or radiotherapy for other malignancies.

The 60+ subgroup consisted of 7 males and 2 females. Six patients were in the "very elderly" category, that is, older than 65 years; three patients were older than 70 years of age. In the subgroup, the median and mean ages were 67.9 and 67.1 years, respectively. Based on the Sanz score, 3 patients were low-risk, 4 patients were intermediate-risk and 1 patient had a high risk of the disease. With respect to the pathogenesis, the disease was defined as secondary in 2 cases. One was that of a 60 -yearold female successfully treated (hysterectomy, radiotherapy) for cervical cancer 5 years before being diagnosed with APL. The other was a 61-year-old male who had been followed and repeatedly treated with chemotherapy for peripheral $\mathrm{T}$ cell non-Hodgkin's lymphoma (T-NHL) in our center prior to the diagnosis of APL. All patients had the classical hypergranular morphological variant of APL.

For a retrospective assessment of comorbidities, the hematopoietic cell transplantation-specific comorbidity index (HCT-CI) by Sorror et al. was used [11]. According to the index, patients with score 0 had a low risk, those with scores 1 and 2 had an intermediate risk and patients scoring 3 or more were in a high-risk group. In our group, three patients scored 0 , two scored 3 , three scored 4 and one patient scored 8 . The median score was 3 , that is, suggesting a high risk.

All patients were treated with a combination of ATRA and anthracyclines. The treatment protocols varied with respect to the time periods of treatment of individual patients. The first patient in the 60+ subgroup was treated from 1994. Induction therapy with ATRA + idarubicin was followed by 2 cycles of consolidation therapy $(7+3$ and $5+2$ with daunorubicin) and two-year maintenance therapy with ATRA + 6-mercaptopurine (6-MP) + methotrexate (MTX). Another 4 patients, diagnosed in 1999-2005, were treated according to the GIMEMA protocol (Table 1) irrespective of their Sanz scores.

Three patients diagnosed after 2008 were treated according to the PETHEMA protocol (Table 2). Treatment of one of these patients (male, 70 years) was dramatically reduced due to complications after non-reduced induction therapy. After remission was achieved and the patient was discharged from hospital, pseudomembranous colitis developed with subsequent multiorgan failure requiring long-term hospital stay that postponed consolidation chemotherapy. As late as 5 months after initiation of induction therapy, bridging therapy with ATRA was started (without chemotherapy, four 2-week cycles followed by 2 -week pauses) and as late as 9 months from the initiation of induction, consolidation therapy was started, with anthracycline doses reduced to $50 \%$.

The last patient, diagnosed in 2012, has received individualized therapy as described in a case report below.

All patients underwent maintenance therapy.

\section{Results}

Out of the 9 patients, eight (89\%) achieved CR. Only one patient died of intracranial hemorrhage 3 days after the diagnosis of APL was made. The bleeding had occurred prior to his admission to our center. This was the only patient with leukocytosis at the time of diagnosis; therefore, he was classified as having a high risk according to Sanz et al. and his HCT-CI score was 4.

Table 1. Protocol for treatment of APL according to the GIMEMA/EORTC 06952

\begin{tabular}{|c|c|}
\hline Induction: & ATRA $45 \mathrm{mg} / \mathrm{m}^{2}$ daily in 2 doses until hematologic remission is achieved + idarubicin $12 \mathrm{mg} / \mathrm{m}^{2}$ daily on days $2,4,6$ and 8 \\
\hline 1st consolidation: & cytosine arabinoside $1 \mathrm{~g} / \mathrm{m}^{2}$ once daily + idarubicin $5 \mathrm{mg} / \mathrm{m}^{2}$ once daily (4 days) \\
\hline 2nd consolidation: & mitoxantrone $10 \mathrm{mg} / \mathrm{m}^{2}$ once daily + etoposide $100 \mathrm{mg} / \mathrm{m}^{2}$ once daily ( 5 days) \\
\hline 3rd consolidation: & $\begin{array}{l}\left.\text { cytosine arabinoside } 150 \mathrm{mg} / \mathrm{m}^{2} / 8 \text { hours s.c. ( } 5 \text { days) }+ \text { idarubicin } 12 \mathrm{mg} / \mathrm{m}^{2} \text { once daily (day } 1\right)+6 \text {-thioguanine } 70 \mathrm{mg} / \mathrm{m}^{2} \text { three } \\
\text { times daily ( } 5 \text { days) }\end{array}$ \\
\hline Maintenance: & 2 years of ATRA (15 days every 3 months) +/- MTX +/- 6-MP \\
\hline
\end{tabular}

Table 2. Protocol for treatment of APL according to the PETHEMA LPA 99

\begin{tabular}{ll}
\hline Induction: & ATRA $45 \mathrm{mg} / \mathrm{m}^{2}$ daily in 2 doses until hematologic remission is achieved + idarubicin $12 \mathrm{mg} / \mathrm{m}^{2}$ daily on days $2,4,6$ and 8 \\
1st consolidation: & low risk: idarubicin $5 \mathrm{mg} / \mathrm{m}^{2}$ once daily $(4$ days $)$ \\
& intermediate+high risk: idarubicin $7 \mathrm{mg} / \mathrm{m}^{2}$ once daily (4 days $)+$ ATRA $45 \mathrm{mg} / \mathrm{m}^{2}(15$ days $)$ \\
2nd consolidation: & low risk: mitoxantrone $10 \mathrm{mg} / \mathrm{m}^{2}$ once daily $(5$ days $)$ \\
& intermediate+high risk: mitoxantrone $10 \mathrm{mg} / \mathrm{m}^{2}$ once daily ( 5 days $)+$ ATRA $45 \mathrm{mg} / \mathrm{m}^{2}(15$ days $)$ \\
3rd consolidation: & low risk: idarubicin $12 \mathrm{mg} / \mathrm{m}^{2}(1$ day $)$ \\
intermediate+high risk: idarubicin $12 \mathrm{mg} / \mathrm{m}^{2}(2$ days $)+$ ATRA $45 \mathrm{mg} / \mathrm{m}^{2}(15$ days $)$ & 2 years of ATRA (15 days every 3 months $)+$ MTX + 6-MP \\
\hline
\end{tabular}


Of the 8 patients who achieved remission, six were alive at the time of the analysis; then, their median follow-up was 59 months. At 28 months from the diagnosis of APL, one patient with secondary PML died of relapse and progression of primary peripheral T-NHL (initial HCT-CI $=3$ ) being in long-term molecular remission of APL. Another patient (initial $\mathrm{HCT}-\mathrm{CI}=4$ ) died 17 years after the diagnosis of APL, in the remission of leukemia as well. The cause of death was acute myocardial infarction (in a patient with chronic ischemic heart disease).

Case report. A 73-year-old male was admitted for dyspnea to a department of internal medicine in June 2012. He was diagnosed with acute pulmonary embolism and anticoagulation therapy was started without the cause for embolism being found. Laboratory tests revealed bicytopenia. As bone marrow cytology was suggestive of APL the patient was referred to our center. There, the diagnosis of PML/RARapositive APL was confirmed. The initial blood count showed hemoglobin $121 \mathrm{~g} / \mathrm{L}$, white blood cell (WBC) count $1.0 \times 10^{9} / \mathrm{L}$ and platelets $79 \times 10^{9} / \mathrm{L}$ (without previous substitution). Thus, the patient was categorized as having a low risk according to the Sanz score. However, his comorbidities were of great significance as he was very obese (body mass index $=39$ ), having a history of chronic ischemic heart disease, acute transmural inferior wall myocardial infarction, severe left ventricular systolic dysfunction with an ejection fraction of $30 \%$, combined valve disease, surgical aortic valve replacement with a bioprosthesis, paroxysmal ventricular fibrillation and a prolonged QT interval. Other comorbidities included grade III chronic venous insufficiency of the lower limbs, venous ulcers of the right distal leg and gout involving the first metatarsophalangeal joints. Therefore, the HCT-CI was 8. On admission, the patient's Karnofsky score [12] assessing his general condition was 50. Immediately after hospital admission, ATRA therapy was initiated with standard doses. Given the cardiac comorbidities, standard treatment with idarubicin was contraindicated. ATO was not administered immediately to avoid further prolongation of the QT interval. Due to a high WBC count $\left(24.7 \times 10^{9} / \mathrm{L}\right.$ and a doubling time of 24 hours) caused by differentiation effects of ATRA and incipient signs of differentiation syndrome, a single $10-\mathrm{mg}$ idarubicin dose was administered on day 15. Subsequently, after the patient was provided with a temporary pacemaker, ten ATO doses of $10 \mathrm{mg} /$ day were administered. After 34 days of his hospital stay, the patient was discharged to outpatient care and continued with ATRA therapy. On day 45 from initiation of the therapy, sternal puncture was performed that confirmed complete hematologic remission, with persisting PML/RARa-positive disease shown by qualitative PCR in both peripheral blood and bone marrow. Induction therapy with ATRA was continued. After therapeutic options were discussed with the patient preferring only outpatient treatment, maintenance therapy with ATRA + 6-MP + MTX was started on day 82 from the diagnosis. Another PCR analysis of PML/RARa after 26 days of maintenance therapy (day 108 from the diagnosis) yielded negative results. Also 3 other tests using peripheral blood (sternal puncture was refused by the patient) were negative. At the same time, his blood count was normal and overall health status was very good. The patient continues with maintenance therapy.

\section{Discussion}

AML is a disease of the elderly, with the patients' median age being 65-70 years. In the vast majority of patients over 65 years of age, AML is incurable due to a high frequency of unfavorable cytogenetic changes in tumor cells, primarily resistant diseases and unacceptable toxicity of intensive chemotherapy caused by comorbidities. Long-term survival is achieved in only approximately $10 \%$ of patients older than 65 years $[13,14]$.

The age distribution of APL patients is different from that in other forms of AML. The patients' median age is approximately 40-45 years, that is, significantly lower than in patients with other AMLs [15-18]. The disease is rare in children under 10 years of age. Later, the incidence increases, reaches a plateau in early adulthood and remains constant until it decreases after the age of 60 [8]. According to other literature data, however, the incidence remains constant with increasing age [19] or even rises [20-23]. Unlike in other AML subtypes, the increase is not exponential.

The higher age of APL patients is, together with leukocytosis and poorer performance status, considered a primary adverse prognostic factor. Although the effectiveness of treatment of elderly APL patients is no lower than in younger individuals (sensitivity to treatment is the same), there are more early deaths (bleeding) and deaths in remission due to treatmentrelated toxicity [8].

In our center, basic diagnostic and treatment data from all APL patients have been studied, starting from the first patient receiving ATRA and including patients dying early from bleeding complications. This is a complete unselected group of patients that reflects long-term experience of more than 20 years.

The median age of patients in the reported group, that is, 43.5 years, is consistent with the literature data. The 60-70 age group comprised 6 patients (10\%); three patients (5\%) were older than 70 years.

CR was achieved in $89 \%$ of the elderly patients; the early death (ED) rate was $11 \%$. There were no treatment-related deaths and none of the patients have relapsed thus far. The patients' basic characteristics are shown in Table 3.

The treatment outcomes in the elderly were comparable with those in younger patients (Figure 1), with CR being achieved in 54 out of 60 patients (90\%); six patients (10\%) died early and 5 patients (10\%) relapsed.

Future relapses cannot be ruled out in patients with reduced/individualized therapy. So far, the follow-up has been too short to prove that such adapted therapy may lead to long-term remission. However, it is almost certain that with- 
out this treatment, patients' survival would be very short and full-dose therapy would be associated with severe, most likely fatal, complications.

In two recent reviews $[5,24]$ on the management of APL in the elderly, the authors comment on the available published data from both unselected population studies and multicenter clinical trials.

In a report from the Swedish Adult Acute Leukemia Registry by Lehmann et al. [20], patients aged 60 or more accounted for $38 \%$ of the entire group; their ED rate was $50 \%$ and 1-year and 5 -year survival rates were $37 \%$ and $24 \%$, respectively. In a population-based US study, Chen et al. [22] identified 449 patients (32\%) aged 60 or more, with their 1-year and 5-year survival rates being $38 \%$ and $24 \%$, respectively.

Different data were found by multicenter studies. In the cited studies [25-32], patients older than 60 years and those older than 70 years accounted for $6-26 \%$ and $3-9 \%$, respectively. In these studies, elderly patients' treatment outcomes are slightly worse when compared with younger patients, with lower CR (82-90\%) and higher ED (11-18\%) rates. Long-term survival is observed in more than a half of elderly patients. The different outcomes are explained by selection of patients included in clinical trials, namely exclusion of mostly elderly patients unable to receive experimental chemotherapy due to comorbidities.

The presented results correspond with those obtained from clinical trials with patient selection rather than unselected population-based registers. The discrepancy may be due to the relatively small size of the group presented that cannot be statistically compared with data published in studies of large patient groups from multiple centers. Another possible explanation is that this rare condition is underdiagnosed. It cannot be ruled out that a certain proportion of individuals with the disease, in particular elderly patients, are not correctly diagnosed and referred to intensive hematology care centers. It is rather unlikely that over the last 20 years, there has been just a single case of fatal intracerebral hemorrhage in

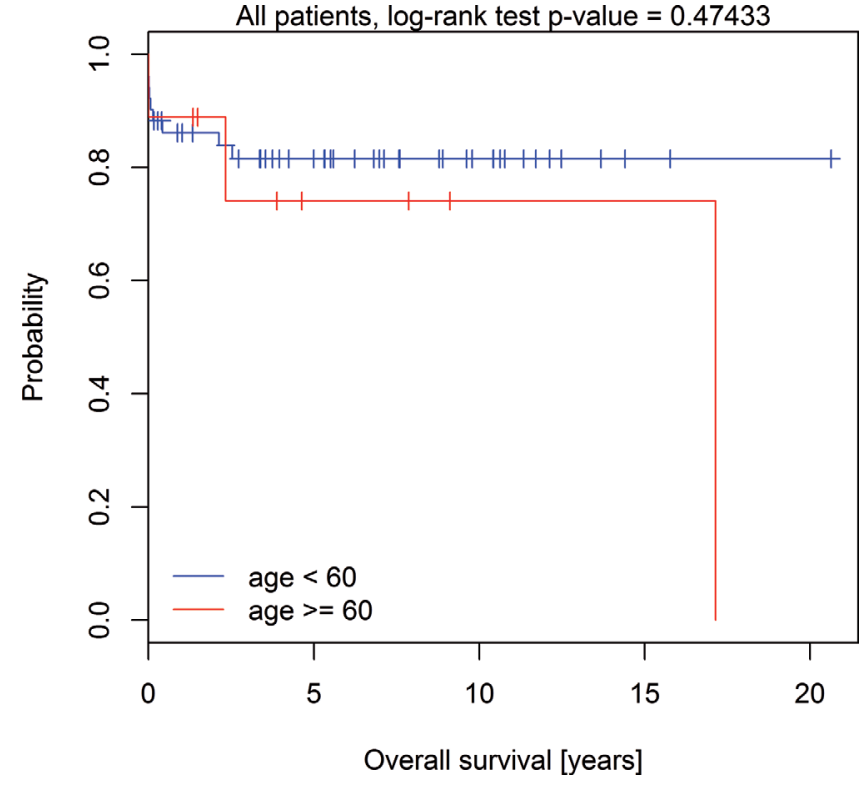

Figure 1. Kaplan-Meier curves for overall survival. OS as stratified by age.

an elderly APL patient in a catchment area with a population of approximately 1 million people.

On the other side, the reported results are very encouraging, showing the future direction of treatment for acute leukemia in elderly patients, the outcomes of which are globally still unsatisfactory.

Treatment of elderly patients with acute promyelocytic leukemia, if administered by an experienced team, may be very successful and its outcomes may be comparable with those achieved in younger age groups. Our experience shows that, unlike in the other forms of AML, a curative approach should always be attempted regardless of age, even in patients with significant comorbidities.

Table 3. Patients - basic characteristics

\begin{tabular}{|c|c|c|c|c|c|c|c|c|}
\hline Gender & Age & Year of dg & Risk (Sanz) & HCT-CI & Therapy & Remission & Cause of death & $\begin{array}{c}\text { Survival from } \\
\text { diagnosis (years) }\end{array}$ \\
\hline male & 64 & 1994 & intermediate & 4 & $7+3$ ATRA $^{1}$ & yes & myocardial infarction & $17.1(+)$ \\
\hline male & 61 & 1999 & low & 3 & GIMEMA & yes & peripheral T-NHL & $2.3(+)$ \\
\hline male & 66 & 2000 & high & 4 & - & no & CNS bleeding & 3 days \\
\hline female & 69 & 2004 & low & 0 & GIMEMA & yes & - & 9.7 \\
\hline male & 73 & 2005 & intermediate & 4 & GIMEMA & yes & - & 8.2 \\
\hline female & 60 & 2008 & low & 3 & PETHEMA & yes & - & 5.5 \\
\hline male & 70 & 2009 & intermediate & 0 & PETHEMA $^{2}$ & yes & - & 4.4 \\
\hline male & 73 & 2012 & low & 8 & individual $^{1}$ & yes & - & 1.6 \\
\hline male & 68 & 2012 & intermediate & 0 & PETHEMA & yes & - & 1.5 \\
\hline
\end{tabular}

${ }^{1}$ see the text for details

${ }^{2}$ reduction - see the text

(+) dead patients 
Acknowledgements: Supported by research projects LF-2014-001 and VZ MSMT CR 6198959205.

\section{References}

[1] ROWLEY JD, GOLOMB HM, DOUGHERTY C. 15/17 Translocation, a consistent chromosomal change in acute promyelocytic leukaemia. Lancet 1977; 1: 549-550 http:// dx.doi.org/10.1016/S0140-6736(77)91415-5

[2] STONE RM, MAYER RJ. The unique aspects of acute promyelocytic leukemia. J Clin Oncol 1990; 8: 1913-1921

[3] FENAUX P, CHOMIENNE C, DEGOS L. Acute promyelocytic leukemia: biology and treatment. Semin Oncol 1997; 24: 92-102

[4] TALLMAN MS, NABHAN C, FEUSNER JH, ROWE JM. Acute promyelocytic leukemia: evolving therapeutic strategies. Blood 2002; 99: 759-767 http://dx.doi.org/10.1182/blood. V99.3.759

[5] LENGFELDER E, HOFMANN WK, NOLTE F. Management of elderly patients with acute promyelocytic leukemia: progress and problems. Ann Hematol 2013; 92: 1181-1188 http://dx.doi.org/10.1007/s00277-013-1788-Z

[6] TALLMAN MS, ALTMAN JK. How I treat acute promyelocytic leukemia. Blood 2009; 114: 5126-5135 http://dx.doi. org/10.1182/blood-2009-07-216457

[7] HUANG ME, YE YC, CHEN SR, CHAI JR, LU JX, et al. Use of all-trans retinoic acid in the treatment of acute promyelocytic leukemia. Blood 1988; 72: 567-572

[8] SANZ MA, GRIMWADE D, TALLMAN MS, LOWENBERG B, FENAUX P, et al. Management of acute promyelocytic leukemia: Recommendations from an expert panel on behalf of the European Leukemia Net. Blood 2009; 113: 1875-1891 http://dx.doi.org/10.1182/blood-2008-04-150250

[9] THOMAS X, PIGNEUX A, RAFFOUX E, HUGUET F, CAILLOT D, et al. Superiority of an arsenic trioxide-based regimen over a historic control combining all-trans retinoic acid plus intensive chemotherapy in the treatment of relapsed acute promyelocytic leukemia. Haematologica 2006; 91: 996-997

[10] SANZMA, LO-COCO F, MARTIN G, AVVISATI G, RAYÓN $\mathrm{C}$, et al. Definition of relapse risk and role of nonanthracycline drugs for consolidation in patients with acute promyelocytic leukemia: a joint study of the PETHEMA and GIMEMA cooperative groups. Blood 2000; 96: 1247-1253

[11] SORROR M, GIRALT S, SANDMAIER BM, LIMA MD, SHAHJAHAN M, et al. Hematopoietic cell transplantation - specific comorbidity index as an outcome predictor for patients with acute myeloid leukemia in first remission: combined FHCRC and MDACC experiences. Blood 2007; 110: 4606-4613 http://dx.doi.org/10.1182/ blood-2007-06-096966

[12] KARNOFSKY DA, BURCHANOT JH. The clinical evaluation of chemotherapeutic agents. New York, New York Columbia Univ. Press; 1949

[13] FERRARA F. Treatment of older patients with acute myeloid leukaemia. Lancet 2010; 376: 1967-1968 http://dx.doi. org/10.1016/S0140-6736(10)62104-6
[14] ERBA HP. Has there been progress in the treatment of older patients with acute myeloid leukemia? Best Practice \& Research Clinical Haematology 2010; 23: 495-501 http://dx.doi. org/10.1016/j.beha.2010.09.012

[15] SANZ MA, MARTIN G, RAYON C, ESTEVE J, GONZÁLEZ $\mathrm{M}$, et al. A modified AIDA protocol with anthracycline-based consolidation results in high antileukemic efficacy and reduced toxicity in newly diagnosed PML/RARalpha-positive acute promyelocytic leukemia. PETHEMA group. Blood 1999; 94: 3015-3021

[16] TALLMAN MS, ANDERSENN JW, SCHIFFER CA, APPELBAUM FR, FEUSNER JH, et al. All-trans-retinoic acid in acute promyelocytic leukemia. N Engl J Med 1997; 337: 10211028 http://dx.doi.org/10.1056/NEJM199710093371501

[17] SANZ MA, LO COCO F, MARTIN G, AVVISATI G, RAYN $\mathrm{C}$, et al. Definition of relapse risk and role of non-anthracycline drugs for consolidation in patients with acute promyelocytic leukemia: a joint study of the PETHEMA and GIMEMA cooperative groups. Blood 2000; 96: 1247-1253

[18] FENAUX P, CHASTANG C, CHEVRET S, SANZ M, DOMBRET $H$, et al. A randomized comparison of all transretinoic acid (ATRA) followed by chemotherapy and ATRA plus chemotherapy and the role of maintenance therapy in newly diagnosed acute promyelocytic leukemia. The European APL Group. Blood 1999; 94: 1192-1200

[19] VICKERS M, JACKSON G, TAYLOR P. The incidence of acute promyelocytic leukemia appears constant over most of a human lifespan, implying only one rate limiting mutation. Leukemia 2000; 14: 722-726 http://dx.doi.org/10.1038/ sj.leu. 2401722

[20] LEHMANN S, RAVN A, CARLSSON L, ANTUNOVIC P, DENEBERG $S$, et al. Continuing high early death rate in acute promyelocytic leukemia: a population-based report from the Swedish Adult Acute Leukemia Registry. Leukemia 2011; 25: 1128-1134 http://dx.doi.org/10.1038/leu.2011.78

[21] DORES GM, DEVESA SS, CURTIS RE, LINET MS, MORTON LM. Acute leukemia incidence and patient survival among children and adults in the United States, 2001-2007. Blood 2012; 119: 34-43 http://dx.doi.org/10.1182/ blood-2011-04-347872

[22] CHEN Y, KANTARJIAN H, WANG H, CORTES J, RAVANDI F. Acute promyelocytic leukemia: a population-based study on incidence and survival in the United States, 1975-2008. Cancer 2012; 118: 5811-5818 http://dx.doi.org/10.1002/ cncr.27623

[23] PARK JH, QIAO B, PANAGEAS KS, SCHYMURA MJ, JURCIC JG, et al. Early death in acute promyelocytic leukemia remains high despite all-trans retinoic acid. Blood 2011; 118: 1248-1254 http://dx.doi.org/10.1182/ blood-2011-04-346437

[24] LO-COCO F, LATAGLIATA R, BRECCIA M. Management of acute promyelocytic leukemia in the elderly. Mediterr J Hematol Infect Dis. 2013; 5: e2013045 http://dx.doi.org/10.4084/ mjhid.2013.045

[25] KANAMARU A, TAKEMOTO Y, TANIMOTO M, MURAKAMI H, ASOU N, et al. All-trans retinoic acid for the treatment of newly diagnosed acute promyelocytic leuke- 
mia. Japan Adult Leukemia Study Group. Blood 1995; 85: 1202-1206

[26] BURNETT AK, GRIMWADE D, SOLOMON E, WHEATLEY K, GOLDSTONE A. Presenting white blood cell counts and kinetics of molecular remission predict prognosis in acute promyelocytic leukemia treated with all-trans retinoic acid: results of the Randomized MRC Trial. Blood 1999; 93: 4131-4143

[27] TALLMAN MS, ANDERSEN JW, SCHIFFER CA, APPELBAUM FR, FEUSNER JH, et al. All-trans retinoic acid in acute promyelocytic leukemia: long-term outcome and prognostic factor analysis from the North American Intergroup protocol. Blood 2002; 100: 4298-4302 http://dx.doi.org/10.1182/ blood-2002-02-0632

[28] FENAUX P, CHASTANG C, CHEVRET S, SANZ MA, DOMBRET H, et al. A randomized comparison of all transretinoic acid (ATRA) followed by chemotherapy and ATRA plus chemotherapy and the role of maintenance therapy in newly diagnosed acute promyelocytic leukemia. The European APL Group. Blood 1999; 94: 1192-1200

[29] SANZ MA, MONTESINOS P, RAYÓN C, HOLOWIECKA A, DE LA SERNA J, et al. Risk-adapted treatment of acute promyelocytic leukemia based on all-trans retinoic acid and anthracycline with addition of cytarabine in consolidation therapy for high-risk patients: further improvements in treatment outcome. Blood 2009; 115: 5137-5146 http://dx.doi. org/10.1182/blood-2010-01-266007

[30] BURNETT AK, HILLS RK, GRIMWADE D, JOVANOVIC JV, CRAIG J, et al. Inclusion of chemotherapy in addition to anthracycline in the treatment of acute promyelocytic leukaemia does not improve outcomes: results of the MRC AML15 Trial. Leukemia 2013; 27: 843-851 http://dx.doi.org/10.1038/ $\underline{\text { leu.2012.360 }}$

[31] LENGFELDER E, HAFERLACH C, SAUSSELE S, HAFERLACH T, SCHULTHEIS B, et al. High dose ara-C in the treatment of newly diagnosed acute promyelocytic leukemia: long-term results of the German AMLCG. Leukemia 2009; 23: 2248-2258 http://dx.doi.org/10.1038/ leu.2009.183

[32] LENGFELDER E, HANFSTEIN B, HAFERLACH C, BRAESS J, KRUG U, et al. Outcome of elderly patients with acute promyelocytic leukemia: results of the German Acute Myeloid Leukemia Cooperative Group. Ann Hematol 2013; 92: 41-52 http://dx.doi.org/10.1007/s00277-012-1597-9 